\title{
Article \\ Pressure-Dependent Clustering in Ionic-Liquid-Poly (Vinylidene Fluoride) Mixtures: An Infrared Spectroscopic Study
}

\author{
Teng-Hui Wang, Wei-Xiang Wang and Hai-Chou Chang *(1) \\ Department of Chemistry, National Dong Hwa University, Shoufeng, Hualien 974, Taiwan; \\ 810712101@gms.ndhu.edu.tw (T.-H.W.); 610812112@gms.ndhu.edu.tw (W.-X.W.) \\ * Correspondence: hcchang@gms.ndhu.edu.tw; Tel.: +886-3-8903585; Fax: +886-3-8900162
}

check for updates

Citation: Wang, T.-H.; Wang, W.-X.; Chang, H.-C. Pressure-Dependent Clustering in Ionic-Liquid-Poly (Vinylidene Fluoride) Mixtures: An Infrared Spectroscopic Study. Nanomaterials 2021, 11, 2099. https://doi.org/10.3390/ nano11082099

Academic Editor: Victor

Genchev Ivanov

Received: 21 July 2021

Accepted: 17 August 2021

Published: 18 August 2021

Publisher's Note: MDPI stays neutral with regard to jurisdictional claims in published maps and institutional affiliations.

Copyright: (C) 2021 by the authors. Licensee MDPI, Basel, Switzerland. This article is an open access article distributed under the terms and conditions of the Creative Commons Attribution (CC BY) license (https:/ / creativecommons.org/licenses/by/ $4.0 /)$.

\begin{abstract}
The nanostructures of ionic liquids (ILs) have been the focus of considerable research attention in recent years. Nevertheless, the nanoscale structures of ILs in the presence of polymers have not been described in detail at present. In this study, nanostructures of ILs disturbed by poly(vinylidene fluoride) (PVdF) were investigated via high-pressure infrared spectra. For 1-(2hydroxyethyl)-3-methylimidazolium bis(trifluoromethanesulfonyl)imide ([HEMIm][TFSI])-PVdF mixtures, non-monotonic frequency shifts of the $\mathrm{C}^{4,5}-\mathrm{H}$ vibrations upon dilution were observed under ambient pressure. The experimental results suggest the presence of microheterogeneity in the [HEMIm][TFSI] systems. Upon compression, PVdF further influenced the local structure of $\mathrm{C}^{4,5}-\mathrm{H}$ via pressure-enhanced IL-PVdF interactions; however, the local structures of $\mathrm{C}^{2}-\mathrm{H}$ and hydrogen-bonded $\mathrm{O}-\mathrm{H}$ were not affected by PVdF under high pressures. For choline [TFSI]-PVdF mixtures, PVdF may disturb the local structures of hydrogen-bonded $\mathrm{O}-\mathrm{H}$. In the absence of the $\mathrm{C}^{4,5}-\mathrm{H} \cdots$ anion and $\mathrm{C}^{2}-\mathrm{H} \cdots$ anion in choline [TFSI]-PVdF mixtures, the $\mathrm{O}-\mathrm{H}$ group becomes a favorable moiety for pressure-enhanced IL-PVdF interactions. Our results indicate the potential of high-pressure application for designing pressure-dependent electronic switches based on the possible changes in the microheterogeneity and electrical conductivity in IL-PVdF systems under various pressures.
\end{abstract}

Keywords: PVdF; [HEMIm][TFSI]; choline [TFSI]; high pressures

\section{Introduction}

As a semi-crystalline polymer, polyvinylidene fluoride (PVdF) consists of five main phase structures, namely $\alpha, \beta, \gamma, \delta$, and $\varepsilon$ phases [1-6]. Owing to the specific conformation of the carbon chain backbone, considerable attention has been paid to the $\beta$ structure of PVdF, which is known to have piezo-, pyro-, and ferroelectric applications [1-9]. Unlike piezoelectric ceramics, piezoelectric polymers such as PVdF are flexible, which may be crucial in the development of wearable electronic mobile devices in the future [1-6]. PVdF and its derivative copolymer (as well as piezoelectric ceramic-PVdF composites) may be promising candidates for tactile sensors, pressure sensors, shock sensors, and thermal measurement devices [1-8]. Following polymerization from 1,1-difluoroethylene $\left(\mathrm{CH}_{2}=\mathrm{CF}_{2}\right)$, PVdF with a $>\mathrm{CF}_{2}$ moiety may interact with cations of ionic liquids (ILs) [10-12]. PVdF does not easily dissolve in many traditional non-toxic solvents, partly because of its outstanding chemical resistance; the addition of a plasticizer may further enhance the flexibility of PVdF-related complexes. The incorporation of ILs into PVdF may modify its physical properties [11]. IL-PVdF mixtures exhibit excellent electrical conductivity, high transparency, and increased ductility. Good piezoelectric properties, surface roughness values, and degrees of crystallinity are also observed for IL-PVdF mixtures $[10,11]$. The addition of ILs can help solve the problem of static charge accumulation on the surfaces of pure polymers. 
Ionic compounds with melting temperatures below the boiling point of water (ILs) are widely used in industry because of their non-volatile, dispersive, and ionic-conductive properties [13-18]. A critical analysis of the structures and properties of ionic liquids was performed by Cabrita's group [13] recently. The interactions between cations and anions in ILs include forces such as electrostatic attraction, van der Waals association, and hydrogen-bonding interactions [13-17,19-23]. The interplay of various interactions in ILs may determine the formation of nanoscale supramolecular domains in bulk ILs. Indeed, the effects of cation-anion associations, such as on viscosity, may influence the properties of ILs. Recently, the mechanisms and properties of ILs that allow for their use as lubricants were extensively reviewed by Calandra et al. [24]. ILs can also be suitable plasticizers to form polymer-salt complexes from PVdF $[10,11]$. As reported in the literature, the $>\mathrm{CF}_{2}$ moiety in PVdF may interact with the IL cation. For example, $>\mathrm{CF}_{2}$ groups in the PVdF chain can interact with the imidazolium C-H of ILs [10,11]. Nevertheless, studies on imidazolium equipped with hydroxyl groups are scarce. Ludwig's group [25] found that ILs with cations containing $-\mathrm{C}_{2} \mathrm{H}_{4} \mathrm{OH}$ group ILs tend to form cationic clusters. Investigations of ILs with cations containing hydroxyl moieties may shed light on cation-anion clusters (caused by electrostatic forces and weak hydrogen bond interactions) and cation-cation associations (attributed to the influence of traditional hydrogen bonds). This is because the ions in ILs are composed of clusters of various sizes owing to various interactions.

Vibrational spectra, such as mid-infrared spectra, may provide information on the environmental changes of functional groups upon blending. Infrared (IR) spectra were used to characterize ion-modified materials in the past. For example, Ivanov et al. [26,27] used a nondestructive infrared technique to inspect ion-modified polymeric materials. Hydroxyl groups are IR-sensitive to changes in local environments, and the formation of $\mathrm{O}-\mathrm{H}$ hydrogen bonds can be easily detected by IR techniques. Moreover, $\mathrm{C}-\mathrm{H}$ can act as a proton donor to form a weak hydrogen bond. When associated with proton acceptor $\mathrm{X}$ to form weak hydrogen bonds $(\mathrm{C}-\mathrm{H} \cdots \mathrm{X}), \mathrm{C}-\mathrm{H}$ covalent bonds sometimes shorten themselves through a blueshift in frequency [20,28-31]. In this work, we investigated the pressure-dependent local structures of ILs with both $\mathrm{O}-\mathrm{H}$ and imidazolium $\mathrm{C}-\mathrm{H}$, which are IR-detectable.

Combining the IR technique and high pressures may result in pressure-enhanced interactions. As reported in previous studies [32-36], the associated structures of ILs were influenced by the addition of PEO [32] and DNA [33] under high pressure. As the pressure was applied, the polymer (PEO or DNA) disturbed the clustering of the ILs, as polymers and ILs interact with specific pressure-enhanced forces. In the current study, two types of ILs (TFSI anion and two types of cations containing hydroxyethyl groups) were used. Upon blending with PVdF, the conformation and clustering change were studied using the IR technique at various pressures.

\section{Materials and Methods}

IL-PVdF mixtures were prepared using poly(vinylidene fluoride) (PVdF, average MW 534,000, Sigma-Aldrich, St. Louis, MO, USA), choline bis(trifluoromethylsulfonyl) imide (choline [TFSI], 99\%, IOLITEC, Heilbronn, Germany), 1-(2-hydroxyethyl)-3-methy limidazolium bis(trifluoromethylsulfonyl)imide ([HEMIm][TFSI], 99\%, UniRegion BioTech, Taoyuan, Taiwan), and N, N-dimethylformamide (DMF, $\geq 99.9 \%$, Sigma-Aldrich, St. Louis, MO, USA). The structures of [HEMIm][TFSI], choline [TFSI], and PVdF are shown in Figure S1 (Supplementary Materials). The numbering of imidazolium atoms is shown in Figure S1. Mixtures of IL-PVdF containing 10, 20, 30, 40, and $50 \mathrm{wt} \%$ of IL were prepared with various weight percentages of IL and PVdF and suitable amounts of DMF were added as the solvent. The solutions were sonicated at room temperature $\left(25^{\circ} \mathrm{C}\right)$ and then stirred at $50{ }^{\circ} \mathrm{C}$ under vacuum. The solvent (DMF) was removed under vacuum and the samples were kept under light in air for at least one day to remove the residual solvent. The samples were further dried at $155^{\circ} \mathrm{C}$ using a moisture analyzer (MS-70, A\&D Company, Tokyo, 
Japan) before spectral measurements were performed. The removal of DMF was confirmed by checking the disappearance of the DMF absorption in the IR spectra.

High pressures (up to $\sim 2 \mathrm{GPa}$ ) were generated using a diamond anvil cell (DAC) equipped with two type IIa diamonds with a culet size of $0.6 \mathrm{~mm}$. In the laboratory, we utilized a Fourier-transform (FT) spectrophotometer (Spectrum RXI, Perkin-Elmer, Naperville, IL, USA) combined with a beam condenser to obtain the IR spectra. The beam condenser was combined with a spectrometer to enhance the intensity of the IR beam. The absorption spectra of the samples were measured and subtracted from those of the DAC to eliminate absorption by the diamond anvils. A $0.25-\mathrm{mm}$-thick Inconel gasket with a $0.3 \mathrm{~mm}$ diameter hole was prepared as the sample holder. Transparent $\mathrm{CaF}_{2}$ crystals were placed in the sample holder before the samples were inserted to avoid the saturation of the IR bands. The pressure calibration followed Wong's method $[37,38]$.

\section{Results and Discussion}

Figure 1 shows infrared spectra of (Figure 1a) pure [HEMIm][TFSI] mixtures of [HEMIm][TFSI]-PVdF containing (Figure 1b) 30, (Figure 1c) 20, and (Figure 1d) $10 \mathrm{wt} \%$ [HEMIm][TFSI], as well as (Figure 1e) pure PVdF obtained at ambient pressure. The IR spectra of pure [HEMIm][TFSI] in Figure 1a show broad O-H absorptions, two main imidazolium C-H bands, and several alkyl C-H peaks at 3300-3700, 3050-3250, and $2800-3000 \mathrm{~cm}^{-1}$, respectively, at ambient pressure [25,32-36]. As shown in Figure 1a, the $\mathrm{O}-\mathrm{H}$ absorption also displays a shoulder peak at ca. $3430 \mathrm{~cm}^{-1}$. The two imidazolium $\mathrm{C}-\mathrm{H}$ bands at 3162 and $3123 \mathrm{~cm}^{-1}$ represent the vibrational absorptions of the $\mathrm{C}^{4,5}-\mathrm{H}$ and $\mathrm{C}^{2}-\mathrm{H}$ groups, respectively, whereas the $\mathrm{C}^{2}-\mathrm{H}$ peak of pure [HEMIm][TFSI] reveals one shoulder band at $3109 \mathrm{~cm}^{-1}$ in Figure 1a. The pure PVdF vibrational spectra in Figure 1e show two main $\mathrm{C}-\mathrm{H}$ absorptions, which are attributed to asymmetric and symmetric $\mathrm{PVdF}$ C-H stretching vibrations at 3021 and $2985 \mathrm{~cm}^{-1}$, respectively [6-8]. Based on the work by Ludwig's group [25], O-H stretching absorptions of pure [HEMIm][TFSI] at ca. 3540 and $3430 \mathrm{~cm}^{-1}$ are related to the $\mathrm{O}-\mathrm{H} \cdots \mathrm{O}=\mathrm{S}$ and $\mathrm{O}-\mathrm{H} \cdots \mathrm{O}-\mathrm{H}$ hydrogen bond interactions. As indicated in Figure 1a, the spectral features of pure [HEMIm][TFSI] in the region of $3300-3700 \mathrm{~cm}^{-1}(\mathrm{O}-\mathrm{H}$ bands) suggest that the pure [HEMIm][TFSI] contains a cation-anion hydrogen bonding association $\left(3539 \mathrm{~cm}^{-1}\right)$ and cationic clusters $\left(3430 \mathrm{~cm}^{-1}\right)$ at atmospheric pressure. Minor absorptions in the $3600-3800 \mathrm{~cm}^{-1}$ region become obvious in [HEMIm][TFSI]-PVdF mixtures containing 30, 20, and $10 \mathrm{wt} \%$ of [HEMIm][TFSI], as shown in Figure $1 \mathrm{~b}-\mathrm{d}$, respectively. The minor O-H peak-for example at $3634 \mathrm{~cm}^{-1}$ for the $30 \mathrm{wt} \%$ [HEMIm][TFSI]-PVdF mixture in Figure $1 \mathrm{~b}$ - may be assigned to the partially free $\mathrm{O}-\mathrm{H}$ moiety of the cation. In the literature, the formation of $\mathrm{H}$-bonding causes a redshift (lower shift) in the frequency of $\mathrm{O}-\mathrm{H}$ stretching vibrations $[20,23,28,29]$. As such, the breakage of H-bonding may induce a blueshift (higher shift) in frequency for the $\mathrm{O}-\mathrm{H}$ vibrational mode; that is, the experimental results of [HEMIm][TFSI]-PVdF mixtures in Figure $1 \mathrm{~b}-\mathrm{d}$ may demonstrate not only the existence of cation-anion and cation-cation clusters, but also increases in the amounts of smaller clusters and isolated cations upon dilution with PVdF.

The concentration dependences of cationic $\mathrm{C}-\mathrm{H}$ and $\mathrm{O}-\mathrm{H}$ stretching frequencies of [HEMIm][TFSI]-PVdF mixtures are shown in Figure 2 to illustrate the divisions of [HEMIm][TFSI] associations into smaller clusters by PVdF. In Figure 2a,c, the O-H and $\mathrm{C}^{2}-\mathrm{H}$ stretching band frequencies show negligible changes with various PVdF concentrations. In contrast, the $\mathrm{C}^{4,5}-\mathrm{H}$ peak in Figure $2 \mathrm{~b}$ show negligible frequency shifts in the region of high [HEMIm][TFSI] concentrations (above $30 \mathrm{wt} \%$ ) of [HEMIm][TFSI] and non-negligible shifts at diluted [HEMIm][TFSI] concentrations (below $30 \mathrm{wt} \%$ ). The nonmonotonic frequency shifts of the $\mathrm{C}^{4,5}-\mathrm{H}$ vibrations in Figure $2 \mathrm{~b}$ at various concentrations may reflect the presence of microheterogeneity in the [HEMIm][TFSI] systems. PVdF seems to disturb the intercluster and intracluster associations in the concentrated and diluted regions, respectively. Researchers have concluded that imidazolium $\mathrm{C}-\mathrm{H}$ absorptions $\left(\mathrm{C}^{2}-\mathrm{H}\right.$ and $\left.\mathrm{C}^{4,5}-\mathrm{H}\right)$ reveal different acidic characteristics, while $\mathrm{C}^{2}-\mathrm{H}$ shows stronger hy- 
drogen bonding interactions than $\mathrm{C}^{4,5}-\mathrm{H}$ [39]. In addition, anions prefer to have close contact with the $\mathrm{C}^{2}-\mathrm{H}$ of the imidazolium ring [39]. As PVdF blends into [HEMIm][TFSI], the IL clusters may be divided by the polymer into smaller clusters by the formation of $\mathrm{C}^{4,5}-\mathrm{H} \cdots \mathrm{PVdF}$ interactions (i.e., breaking the $\mathrm{C}^{4,5}-\mathrm{H} \cdots$ anion interaction), leading to the blueshift of $\mathrm{C}^{4,5}-\mathrm{H}$ at low concentrations of [HEMIm][TFSI] for [HEMIm][TFSI]-PVdF mixtures, as shown in Figure $2 b$.

Figure 3 shows the IR spectral features of pure [HEMIm][TFSI] at various pressures. As the pressure increases, the $\mathrm{C}^{2}-\mathrm{H}$ and $\mathrm{C}^{4,5}-\mathrm{H}$ bands show a blueshift accompanied by mildband broadening. In contrast to $\mathrm{C}-\mathrm{H}$ absorption, the $\mathrm{O}-\mathrm{H}$ stretching bands show a redshift as the pressure is increased from ambient pressure to $2.5 \mathrm{GPa}$, as shown in Figure 3. The results in Figure 3 demonstrate that $\mathrm{C}^{2}-\mathrm{H}$ and $\mathrm{C}^{4,5}-\mathrm{H}$ may suffer pressure-induced changes in weak hydrogen-bonding interactions (a blueshift) with anions [32-36]. Conversely, the pressure-induced redshift of the $\mathrm{O}-\mathrm{H}$ vibrational bands may result from both pressureenhanced strong hydrogen bonding and the formation of larger cationic clusters (lower frequencies accompanied by band broadening) via pressure-induced association [32-36].



Figure 1. IR spectra of (a) pure [HEMIm][TFSI] and mixture of PVdF containing (b) 30, (c) 20, and (d) $10 \mathrm{wt} \%$ [HEMIm][TFSI] and (e) pure PVdF at ambient pressure. 

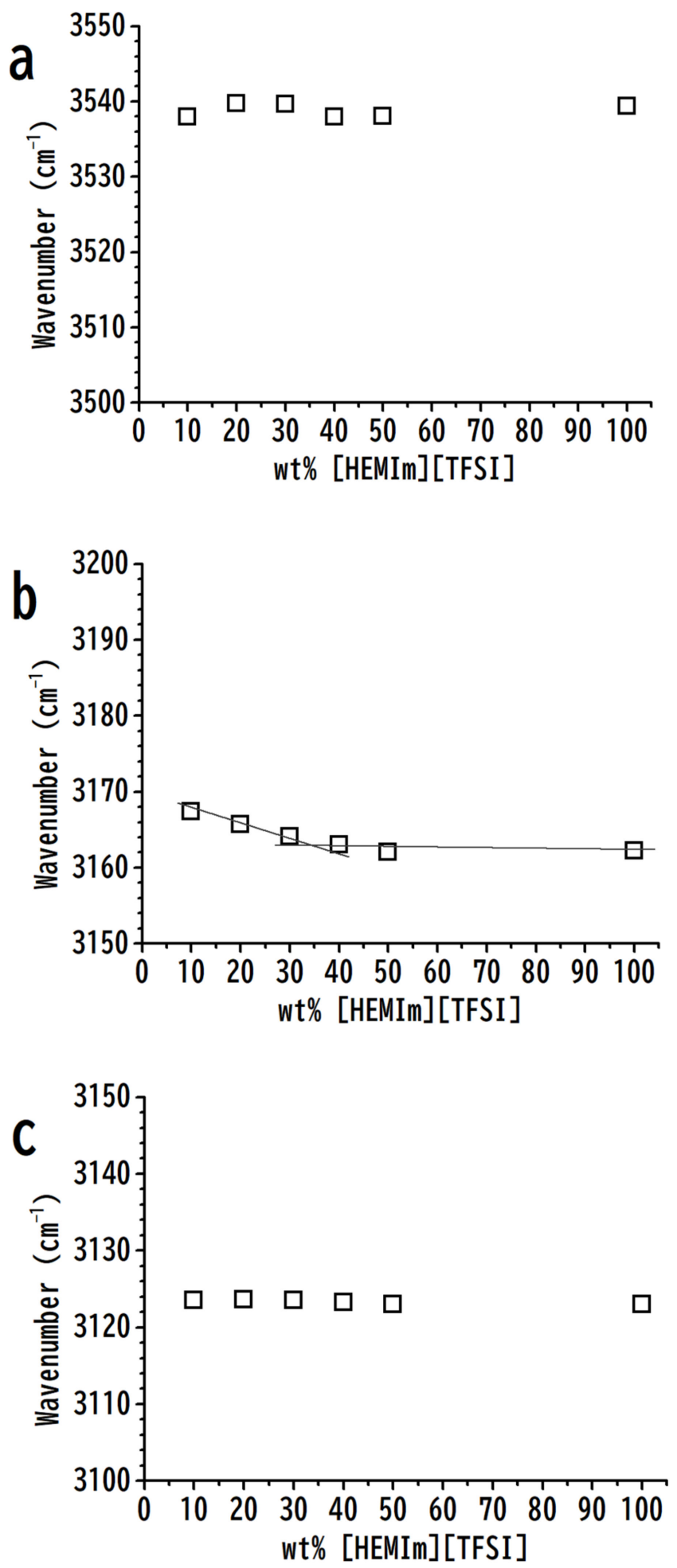

Figure 2. Concentration dependences of (a) hydroxy $\mathrm{O}-\mathrm{H}$, (b) imidazolium $\mathrm{C}^{4,5}-\mathrm{H}$, and (c) imidazolium $\mathrm{C}^{2}-\mathrm{H}$ stretching bands of [HEMIm][TFSI]-PVdF mixtures as a function of the weight percentage of [HEMIm][TFSI]. 




Figure 3. IR spectra of pure [HEMIm][TFSI] at (a) ambient pressure and at (b) 0.4, (c) 0.7, (d) 1.1, (e) 1.5 , (f) 1.8 , and (g) $2.5 \mathrm{GPa}$.

Figure 4 shows IR spectra of a mixture containing $10 \mathrm{wt} \%$ [HEMIm][TFSI] at (Figure 4a) ambient pressure and at (Figure 4b) 0.4, (Figure 4c) 0.7, (Figure 4d) 1.1, (Figure 4e) 1.5, (Figure 4f) 1.8, and (Figure 4g) 2.5 GPa. In Figure 4, the imidazolium C-H absorptions show a blueshift as the pressure increases from ambient pressure in Figure 4a to $2.5 \mathrm{GPa}$ in Figure $4 \mathrm{~g}$. The two main $\mathrm{O}-\mathrm{H}$ stretching bands at ca. 3538 and $3639 \mathrm{~cm}^{-1}$ show a redshift as the pressure increases, as shown in Figure 4. The peak broadening of the $\mathrm{O}-\mathrm{H}$ band at ca. $3538 \mathrm{~cm}^{-1}$ becomes obvious at high pressures. We note that the intensity ratio of $\mathrm{I}_{3538} / \mathrm{I}_{3639}$ decreases upon compression. The ratio of $\mathrm{I}_{3538}$ and $\mathrm{I}_{3639}$ represents the proportions of larger cation-anion clusters and isolated $\mathrm{O}-\mathrm{H}$ in the [HEMIm][TFSI]-PVdF mixture with $10 \mathrm{wt} \%$ [HEMIm][TFSI]. $\mathrm{I}_{3538} / \mathrm{I}_{3639}$ may provide information about the specific local structural changes as high pressure is introduced to the mixture. The decreases in $\mathrm{I}_{3538} / \mathrm{I}_{3639}$ under high pressures suggest that PVdF may further separate the IL clusters into free $\mathrm{O}-\mathrm{H}$ cations via pressure-enhanced PVdF-IL interactions. A minor band at ca. $3690 \mathrm{~cm}^{-1}$ arises at high pressures in Figure $4 \mathrm{~d}-\mathrm{g}$. The observation of 3640 and $3690 \mathrm{~cm}^{-1}$ peaks suggests the presence of at least two local environments for isolated $\mathrm{O}-\mathrm{H}$ structures due to PVdF-IL interactions under high pressures. Figures S2 and S3 (in the Supplementary Materials) illustrate pressure-dependent IR spectra of the mixture with $20 \mathrm{wt} \%$ [HEMIm][TFSI] and pure PVdF, respectively. 


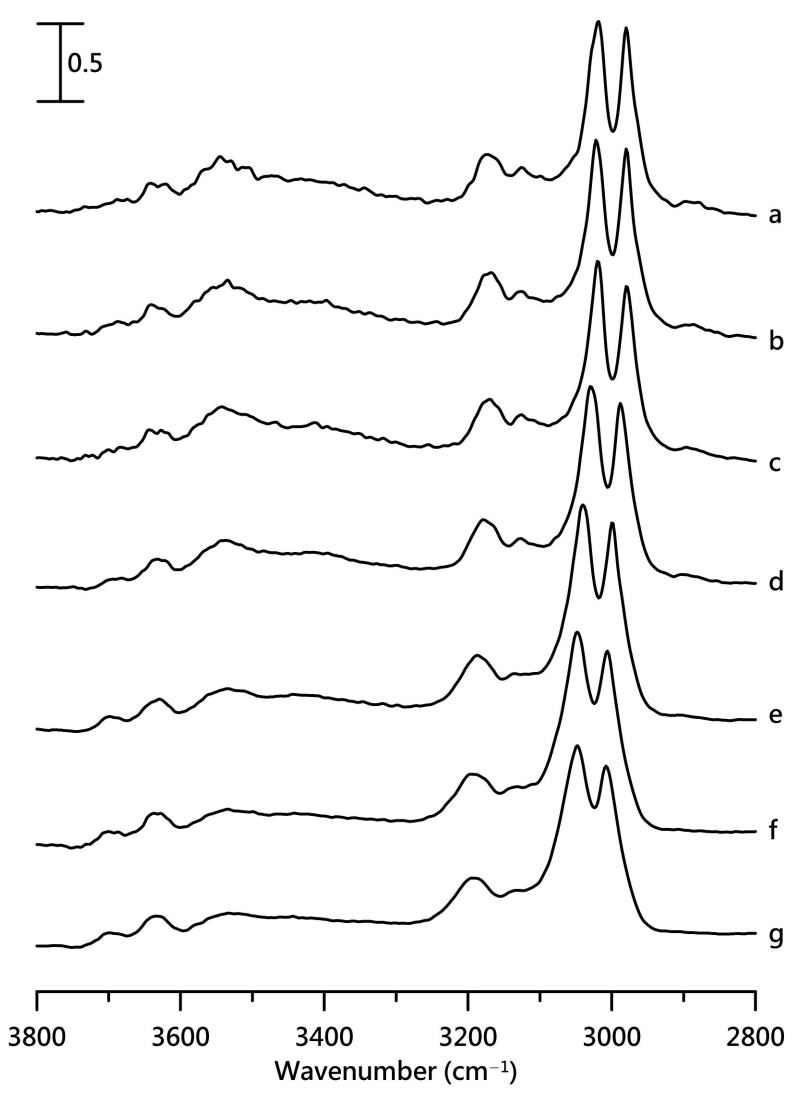

Figure 4. IR spectra of mixture of PVdF containing $10 \mathrm{wt} \%$ [HEMIm][TFSI] at (a) ambient pressure and at (b) 0.4, (c) 0.7, (d) 1.1, (e) 1.5, (f) 1.8, and (g) 2.5 GPa.

The pressure dependences of the $\mathrm{O}-\mathrm{H}, \mathrm{C}^{4,5}-\mathrm{H}$, and $\mathrm{C}^{2}-\mathrm{H}$ stretching frequencies for various concentrations are displayed in Figure 5. Figure 5a shows the redshifts of the hydrogen-bonded $\mathrm{O}-\mathrm{H}$ stretching band upon compression for both pure [HEMIm][TFSI] and mixtures; however, the addition of PVdF does not induce remarkable changes in the $\mathrm{O}-\mathrm{H}$ stretching frequency in Figure $5 \mathrm{a}$ at any pressure. The results in Figure 5a indicate that PVdF may not further influence the local structures of hydrogen-bonded $\mathrm{O}-\mathrm{H}$ upon compression. The imidazolium ring $\mathrm{C}^{4,5}-\mathrm{H}$ band frequencies increased from $3179 \mathrm{~cm}^{-1}$ (pure [HEMIm][TFSI]) to $3194 \mathrm{~cm}^{-1}$ (10 $\mathrm{wt} \%$ mixture) under a pressure of $2.5 \mathrm{GPa}$. We note that the $\mathrm{C}^{4,5}-\mathrm{H}$ stretching frequencies are 3162 and $3167 \mathrm{~cm}^{-1}$ for pure [HEMIm][TSFI] and $10 \mathrm{wt} \%$ mixture, respectively, under ambient pressure, as shown in Figure $5 \mathrm{~b}$. Traditional hydrogen-bonded $\mathrm{O}-\mathrm{H} \cdots$ anion associations may remain strong under high pressures, as demonstrated in Figure 5a, while the weaker $\mathrm{C}^{4,5}-\mathrm{H} \cdots$ anion interactions are likely disturbed by pressure-enhanced IL-PVdF interactions, as shown in Figure 5b. In short, in comparison with pure [HEMIm] [TFSI], the addition of polymer material (PVdF) may disturb the local structures of $\mathrm{C}^{4,5}-\mathrm{H}$ in mixtures of [HEMIm][TFSI]-PVdF upon compression, as indicated in Figure $5 \mathrm{~b}$. As shown in Figure $5 \mathrm{c}$, the $\mathrm{C}^{2}-\mathrm{H}$ stretching frequencies of pure [HEMIm][TFSI] and [HEMIm][TFSI]-PVdF mixtures demonstrate similar tendencies upon compression; that is, the local environment of $\mathrm{C}^{2}-\mathrm{H}$ may not be easily interfered with by PVdF under high pressures. These observations agree with the fact that $\mathrm{C}^{2}-\mathrm{H}$ has stronger acidity than $\mathrm{C}^{4,5}-\mathrm{H}$, while $\mathrm{C}^{2}-\mathrm{H} \cdots$ anion hydrogen-bonding interactions are more attractive than $\mathrm{C}^{4,5}-\mathrm{H} \cdots$ anions. 


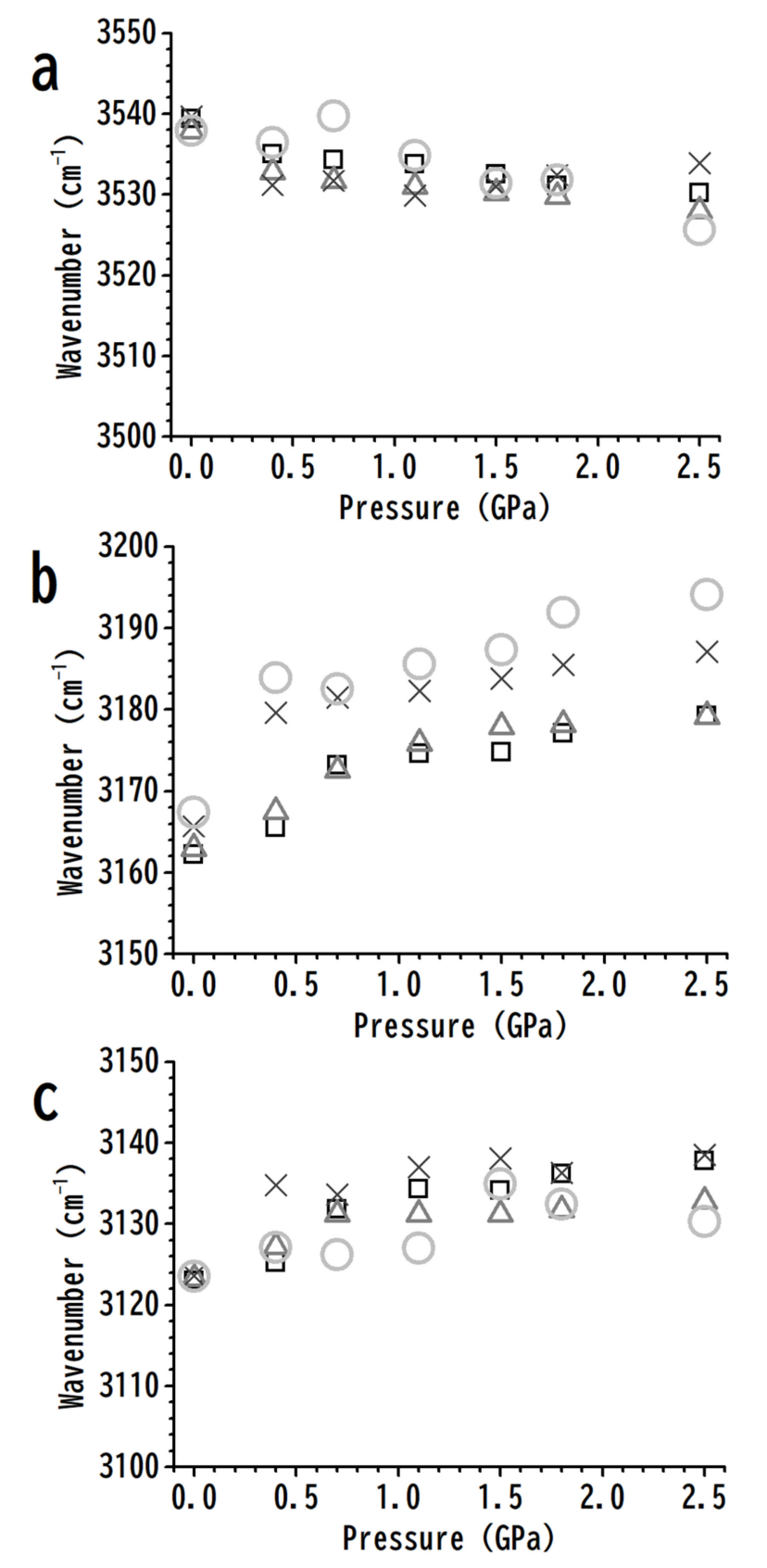

Figure 5. Pressure dependences of the $\mathrm{O}-\mathrm{H}$ and $\mathrm{C}-\mathrm{H}$ stretching frequencies of cation $\mathrm{O}-\mathrm{H}(\mathbf{a})$, $\mathrm{C}^{4,5}-\mathrm{H}(\mathbf{b})$, and $\mathrm{C}^{2}-\mathrm{H}(\mathbf{c})$ for pure [HEMIm] [TFSI] (squares) and for [HEMIm][TFSI]-PVdF mixtures containing 40 (triangles), 20 (crosses), and 10 (circles) wt $\%$ [HEMIm][TFSI].

For pure [HEMIm][TFSI], the imidazolium and anions may involve at least three kinds of associations: $\mathrm{O}-\mathrm{H} \cdots$ anions, $\mathrm{C}^{4,5}-\mathrm{H} \cdots$ anions, and $\mathrm{C}^{2}-\mathrm{H} \cdots$ anions. As the polymer is added to [HEMIm][TFSI] to form [HEMIm][TFSI]-PVdF mixtures, the weaker interactions between imidazolium and the anion may be disturbed by the PVdF molecule. As shown in Figure 5, the stretching frequencies of $\mathrm{C}^{4,5}-\mathrm{H}$ are significantly influenced by PVdF via pressure-enhanced $\mathrm{C}^{4,5}-\mathrm{H} \cdots \mathrm{PVdF}$ interactions. The $\mathrm{C}^{4,5}-\mathrm{H} \cdots$ anion seems to be the weakest interaction when compared to the $\mathrm{O}-\mathrm{H} \cdots$ anion and $\mathrm{C}^{2}-\mathrm{H} \cdots$ anion at high pressures.

In order to shed more light on the association between cations and anions, choline [TFSI] was studied. Figure 6 shows the IR spectra for pure choline [TFSI], three choline [TFSI]-PVdF mixtures with various concentrations, and pure PVdF obtained at ambient 
pressure. The spectrum of pure choline [TFSI] in Figure 6a shows broad O-H absorption at ca. $3541 \mathrm{~cm}^{-1}$ and alkyl C-H stretching bands located in the region of $800-3100 \mathrm{~cm}^{-1}$. The pure PVdF IR spectrum in Figure 6e shows two dominant $\mathrm{C}-\mathrm{H}$ stretching bands in the region from 2900 to $3150 \mathrm{~cm}^{-1}$. Unfortunately, the choline $\mathrm{C}-\mathrm{H}$ absorption overlaps with the PVdF C-H bands in the region from 2800 to $3100 \mathrm{~cm}^{-1}$ (Figure 6); thus, we focused on $\mathrm{O}-\mathrm{H}$ stretching in the region from 3200 to $3800 \mathrm{~cm}^{-1}$ for the mixtures. As choline [TFSI] is diluted by the polymer, an additional peak appears at ca. $3630 \mathrm{~cm}^{-1}$ for choline [TFSI]-PVdF mixtures, as is shown in Figure $6 \mathrm{~b}-\mathrm{d}$. The peak above $3600 \mathrm{~cm}^{-1}$ for mixtures of choline [TFSI]-PVdF in Figure $6 \mathrm{~b}-\mathrm{d}$ was regarded as the free $\mathrm{O}-\mathrm{H}$ stretching of choline cations or partially dissociated clusters for choline [TFSI]. PVdF may tend to change the local structures of the $\mathrm{O}-\mathrm{H}$ moiety by cutting the hydrogen-bonded network of choline [TFSI] into small clusters or free cations.

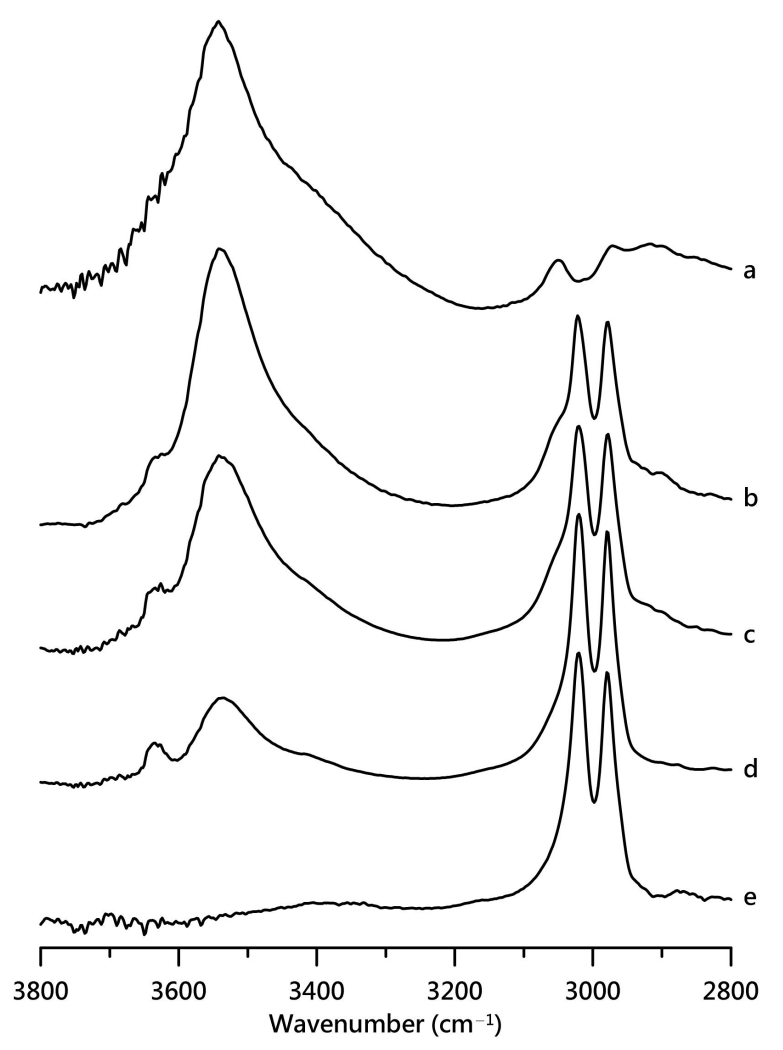

Figure 6. IR spectra of (a) pure choline [TFSI]; mixtures of PVdF containing (b) 30, (c) 20, and (d) $10 \mathrm{wt} \%$ choline [TFSI]; and (e) pure PVdF at ambient pressure.

Figure 7 illustrates the concentration dependences of the $\mathrm{O}-\mathrm{H}$ stretching bands of choline [TFSI]-PVdF mixtures as a function of the weight percentage of choline [TFSI]. As shown in Figure 7, the O-H stretching band of pure choline [TFSI] at ca. $3541 \mathrm{~cm}^{-1}$ is red-shifted to $3534 \mathrm{~cm}^{-1}$ for the mixture with $10 \mathrm{wt} \%$ choline [TFSI]. The redshifts of the hydrogen-bonded $\mathrm{O}-\mathrm{H}$ bands were not observed for the [HEMIm][TFSI]-PVdF mixture (Figure 2a). The [HEMIm] cation has three possible hydrogen-bonding sites for cationanion interactions $\left(\mathrm{C}^{4,5}-\mathrm{H} \cdots\right.$ anion, $\mathrm{C}^{2}-\mathrm{H} \cdots$ anion, and $\mathrm{O}-\mathrm{H} \cdots$ anion), whereas choline [TFSI] has only $\mathrm{O}-\mathrm{H} \cdots$ anions. As the polymer was mixed with choline [TFSI], PVdF may have disturbed the local structure of the hydrogen-bonded $\mathrm{O}-\mathrm{H}$ of choline, owing to the lack of more favorable options. 


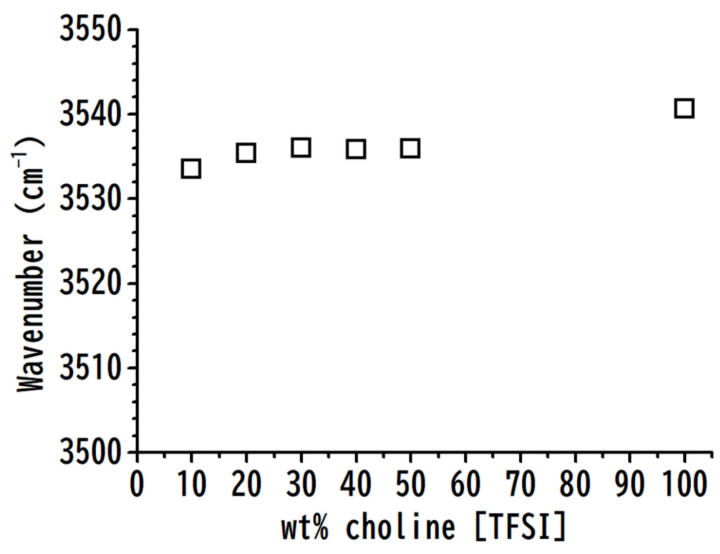

Figure 7. Concentration dependences of hydroxy O-H stretching bands of choline [TFSI]-PVdF mixtures as a function of the weight percentage of choline [TFSI].

Figure 8 shows the IR spectra of the $10 \mathrm{wt} \%$ choline [TFSI]-PVdF mixture under various pressures. At the ambient pressure, the spectrum of the $10 \mathrm{wt} \%$ mixture reveals $\mathrm{O}-\mathrm{H}$ absorptions at 3534 and $3633 \mathrm{~cm}^{-1}$, which may be owing to the cation-anion hydrogen bonding network and free-like $\mathrm{O}-\mathrm{H}$ of choline (Figure 8a). As the pressure increases (Figure 8b-g), the spectra show three distinguishable $\mathrm{O}-\mathrm{H}$ bands at ca. 3532, 3622, and $3686 \mathrm{~cm}^{-1}$, corresponding to hydrogen bonding $\mathrm{O}-\mathrm{H}$ networks and two free-like $\mathrm{O}-\mathrm{H}$ structures, respectively. Furthermore, the intensity ratio of hydrogen bonding $\mathrm{O}-\mathrm{H}$ absorption to free-like $\mathrm{O}-\mathrm{H}$ absorption $\left(\mathrm{I}_{3532} /\left(\mathrm{I}_{3622}+\mathrm{I}_{3686}\right)\right)$ decreases as the pressure increases to $2.5 \mathrm{GPa}$, as shown in Figure $5 \mathrm{~g}$. The decrease in the ratio may indicate that the percentage of free $\mathrm{OH}$ increases in the $10 \mathrm{wt} \%$ choline [TFSI]-PVdF mixture upon compression. These results may be attributed to the insertion of $\mathrm{PVdF}$ into the cation-anion aggregations via pressure-induced interactions, while the polymer molecules may provide at least two surroundings for the free $\mathrm{OH}$ group. The IR spectra of pure choline [TFSI] at various pressures are shown in Figure S4.

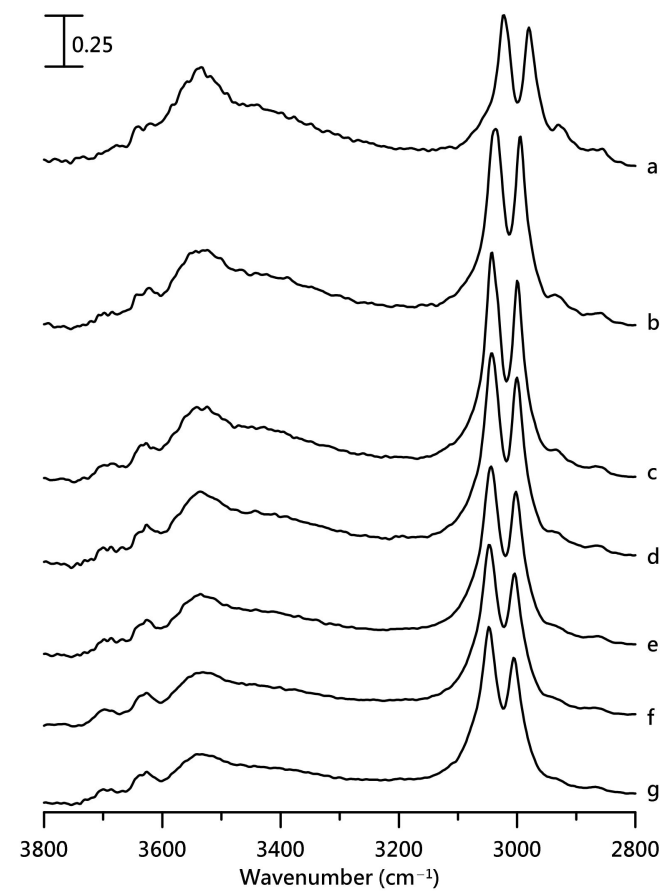

Figure 8. IR spectra of mixture of PVdF containing $10 \mathrm{wt} \%$ choline [TFSI] at (a) ambient pressure and at (b) 0.4, (c) 0.7, (d) 1.1, (e) 1.5, (f) 1.8, and (g) 2.5 GPa. 
Figure 9 shows the pressure dependence of the $\mathrm{O}-\mathrm{H}$ stretching frequencies of pure choline [TFSI] and two choline [TFSI]-PVdF mixtures (containing 30 and $10 \mathrm{wt} \%$ choline [TFSI]). In Figure 9, the O-H stretching frequencies reveal mild redshifts from $3541 \mathrm{~cm}^{-1}$ (pure choline [TFSI]) to $3534 \mathrm{~cm}^{-1}(10 \mathrm{wt} \%$ mixture) under ambient pressure. In contrast, large redshifts from $3548 \mathrm{~cm}^{-1}$ (pure choline [TFSI]) to $3531 \mathrm{~cm}^{-1}$ (10 wt $\%$ mixture) were detected at a pressure of $2.5 \mathrm{GPa}$. We note that such significant redshifts under high pressures in Figure 9 are not observed in the $\mathrm{O}-\mathrm{H}$ of the [HEMIm][TFSI] systems in Figure $5 \mathrm{a}$. In the absence of weaker interactions (such as $\mathrm{C}^{4,5}-\mathrm{H} \cdots$ anion), the $\mathrm{O}-\mathrm{H}$ group is a favorable site for pressure-enhanced cation-PVdF interactions in choline [TFSI]-PVdF mixtures.

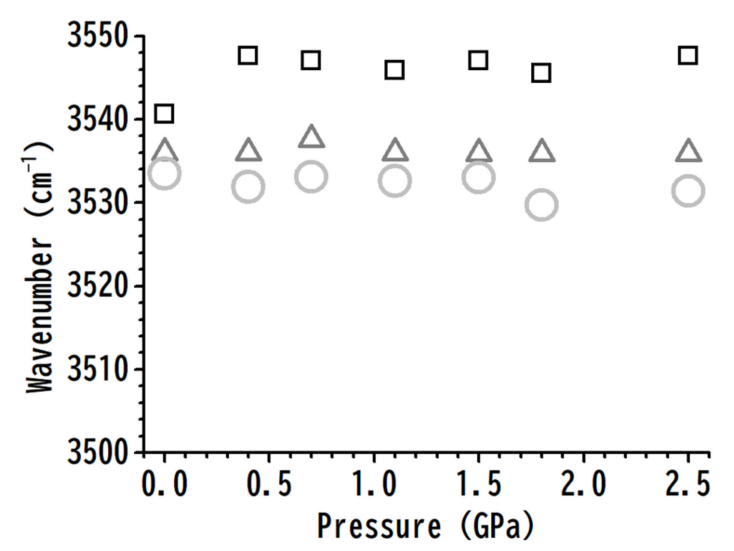

Figure 9. Pressure dependences of the $\mathrm{O}-\mathrm{H}$ stretching frequencies of cations for pure choline [TFSI] (squares) and choline [TFSI]-PVdF mixtures containing 30 (triangles) and 10 (circles) $\mathrm{wt} \%$ choline [TFSI].

\section{Conclusions}

In this study, we demonstrated that the presence of PVdF can influence the clustering structures of [HEMIm][TFSI] and choline [TFSI]. The increase in free -OH absorption at ca. $3634 \mathrm{~cm}^{-1}$ for diluted IL-PVdF mixtures suggest an increase in the number of smaller clusters and isolated cations upon dilution at ambient pressure. As the pressure increased, the $\mathrm{C}^{4,5}-\mathrm{H} \cdots$ anion associations were likely further disturbed by pressureenhanced [HEMIm][TFSI]-PVdF interactions. Upon compression, PVdF tended to modify the local structure of the hydrogen bond $\mathrm{O}-\mathrm{H}$ in choline [TFSI]-PVdF mixtures. The results suggest that high pressure can change the clustering structures and might be successful in modifying the electrochemical properties (such as electric conductivity) of IL-PVdF mixtures. The differences in clustering structures under various pressures may suggest the potential of IL-PVdF mixtures to serve as pressure-dependent electronic switches. Hopefully, the experimental results presented in this study may stimulate further simulation research in the future to rationalize the structural changes of IL-PVdF mixtures in detail under high pressures.

Supplementary Materials: The following are available online at https:/ /www.mdpi.com/article/10 .3390/nano11082099/s1: Figure S1: Structure of [HEMIm][TFSI], choline [TFSI], and PVdF. Figure S2: IR spectra of mixture of PVdF containing $20 \mathrm{wt} \%$ [HEMIm][TFSI] at (a) ambient pressure and at (b) 0.4, (c) 0.7 , (d) 1.1, (e) 1.5, (f) 1.8, and (g) 2.5 GPa. Figure S3: IR spectra of pure PVdF at (a) ambient pressure and at (b) 0.4, (c) 0.7, (d) 1.1, (e) 1.5, (f) 1.8, and (g) 2.5 GPa. Figure S4: IR spectra of pure choline [TFSI] at (a) ambient pressure and at (b) 0.4, (c) 0.7, (d) 1.1, (e) 1.5, (f) 1.8, and (g) 2.5 GPa.

Author Contributions: Formal analysis, T.-H.W.; data curation, W.-X.W.; writing-original draft preparation, T.-H.W.; writing-review and editing, H.-C.C.; supervision, H.-C.C. All authors have read and agreed to the published version of the manuscript.

Funding: This research was funded by Ministry of Science and Technology (contract No. MOST 110-2113-M-259-006) of Taiwan. 
Data Availability Statement: The data presented in this study are available on request from the corresponding author.

Acknowledgments: The authors thank the National Dong Hwa University and Ministry of Science and Technology (Contract No. MOST 110-2113-M-259-002) of Taiwan for financial support. The authors thank Zhu-Yun Zhong, Yu-Fang Chan, Yu-Hsuan Ho, and Wen-Ling Lin for their assistance.

Conflicts of Interest: The authors declare no conflict of interest.

\section{References}

1. Abu Alhasssan, Z.; Burezq, Y.S.; Nair, R.; Shehata, N. Polyvinylidene Difluoride piezoelectric electrospun nanofibers: Review in synthesis, fabrication, characterizations, and applications. J. Nanomater. 2018, 2018, 1-12. [CrossRef]

2. Francis, C.F.J; Kyratzis, I.L.; Best, A.S. Lithium-ion battery separators for ionic-liquid electrolytes: A review. Adv. Mater. 2020, 32, 1904205. [CrossRef]

3. Friess, K.; Izák, P.; Kárászová, M.; Pasichnyk, M.; Lanč, M.; Nikolaeva, D.; Luis, P.; Jansen, J.C. A review on ionic liquid gas separation membranes. Membranes 2021, 11, 97. [CrossRef] [PubMed]

4. Guo, S.; Duan, X.; Xie, M.; Aw, K.; Xue, Q. Composites, fabrication and application of polyvinylidene fluoride for flexible electromechanical devices: A review. Micromachines 2020, 11, 1076. [CrossRef] [PubMed]

5. Lang, S.; Muensit, S. Review of some lesser-known applications of piezoelectric and pyroelectric polymers. Appl. Phys. A 2006, 85, 125-134. [CrossRef]

6. Wang, X.; Sun, F.; Yin, G.; Wang, Y.; Liu, B.; Dong, M. Tactile-sensing based on flexible PVDF nanofibers via electrospinning: A review. Sensors 2018, 18, 330. [CrossRef] [PubMed]

7. Chae, I.; Ahmed, S.; Ben Atitallah, H.; Luo, J.; Wang, Q.; Ounaies, Z.; Kim, S.H. Vibrational Sum frequency generation (SFG) analysis of ferroelectric response of PVDF-based copolymer and terpolymer. Macromolecules 2017, 50, 2838-2844. [CrossRef]

8. Harstad, S.; D'Souza, N.; Soin, N.; El Gendy, A.; Gupta, S.; Pecharsky, V.K.; Shah, T.; Siores, E.; Hadimani, R.L. Enhancement of $\beta$-phase in PVDF films embedded with ferromagnetic Gd5Si4 nanoparticles for piezoelectric energy harvesting. AIP Adv. 2017, 7, 056411. [CrossRef]

9. Li, H.; Tian, C.; Deng, Z. Energy harvesting from low frequency applications using piezoelectric materials. Appl. Phys. Rev. 2014, 1, 041301. [CrossRef]

10. Xing, C.; Zhao, L.; You, J.; Dong, W.; Cao, X.; Li, Y. Impact of ionic liquid-modified multiwalled carbon nanotubes on the crystallization behavior of poly(vinylidene fluoride). J. Phys. Chem. B 2012, 116, 8312-8320. [CrossRef]

11. Xing, C.; Zhao, M.; Zhao, L.; You, J.; Cao, X.; Li, Y. Ionic liquid modified poly(vinylidene fluoride): Crystalline structures, miscibility, and physical properties. Polym. Chem. 2013, 4, 5726-5734. [CrossRef]

12. Bai, H.; Wang, X.; Zhou, Y.; Zhang, L. Preparation and characterization of poly(vinylidene fluoride) composite membranes blended with nano-crystalline cellulose. Prog. Nat. Sci. 2012, 22, 250-257. [CrossRef]

13. Silva, W.; Zanatta, M.; Ferreira, A.S.; Corvo, M.C.; Cabrita, E.J. Revisiting ionic liquid structure-property relationship: A critical analysis. Int. J. Mol. Sci. 2020, 21, 7745. [CrossRef] [PubMed]

14. Chen, S.; Zhang, S.; Liu, X.; Wang, J.; Wang, J.; Dong, K.; Sun, J.; Xu, B. Ionic liquid clusters: Structure, formation mechanism, and effect on the behavior of ionic liquids. Phys. Chem. Chem. Phys. 2014, 16, 5893-5906. [CrossRef]

15. Hogan, C.J., Jr.; Fernandez de la Mora, J. Ion-pair evaporation from ionic liquid clusters. J. Am. Soc. Mass Spectrom. 2010, 21, 1382-1386. [CrossRef] [PubMed]

16. Koßmann, S.; Thar, J.; Kirchner, B.; Hunt, P.A.; Welton, T. Cooperativity in ionic liquids. J. Chem. Phys. 2006, 124, 174506. [CrossRef]

17. Lei, Z.; Chen, B.; Koo, Y.-M.; MacFarlane, D. Introduction: Ionic liquids. Chem. Rev. 2017, 117, 6633-6635. [CrossRef]

18. Osada, I.; De Vries, H.; Scrosati, B.; Passerini, S. Ionic-liquid-based polymer electrolytes for battery applications. Angew. Chem. Int. Ed. 2016, 55, 500-513. [CrossRef]

19. López-Pastor, M.; Ayora-Cañada, M.J.; Valcárcel, M.; Lendl, B. Association of methanol and water in ionic liquids elucidated by infrared spectroscopy using two-dimensional correlation and multivariate curve resolution. J. Phys. Chem. B 2006, 110, 10896-10902. [CrossRef]

20. Matthews, R.P.; Welton, T.; Hunt, P.A. Hydrogen bonding and pi-pi interactions in imidazolium-chloride ionic liquid clusters. Phys. Chem. Chem. Phys. 2015, 17, 14437-14453. [CrossRef]

21. Na, S.; Chaurasia, S.K.; Singh, R.K.; Chandra, S. Thermal stability, complexing behavior, and ionic transport of polymeric gel membranes based on polymer PVdF-HFP and ionic liquid, [BMIM][BF4]. J. Phys. Chem. B 2013, 117, 897-906.

22. Umebayashi, Y.; Jiang, J.-C.; Shan, Y.-L.; Lin, K.-H.; Fujii, K.; Seki, S.; Ishiguro, S.-I.; Lin, S.H.; Chang, H.-C. Structural change of ionic association in ionic liquid/water mixtures: A high-pressure infrared spectroscopic study. J. Chem. Phys. 2009, $130,124503$. [CrossRef]

23. Yokozeki, A.; Kasprzak, D.J.; Shiflett, M.B. Thermal effect on C-H stretching vibrations of the imidazolium ring in ionic liquids. Phys. Chem. Chem. Phys. 2007, 9, 5018-5026. [CrossRef] [PubMed]

24. Calandra, P.; Szerb, E.; Lombardo, D.; Algieri, V.; De Nino, A.; Maiuolo, L. A presentation of ionic liquids as lubricants: Some critical comments. Appl. Sci. 2021, 11, 5677. [CrossRef] 
25. Niemann, T.; Zaitsau, D.; Strate, A.; Villinger, A.; Ludwig, R. Cationic clustering influences the phase behaviour of ionic liquids. Sci. Rep. 2018, 8, 1-7. [CrossRef] [PubMed]

26. Ivanov, V.; Litvinchuk, A.; Todorov, N.; Abrashev, M.; Marinova, V. Infrared response of $\alpha$-and $\beta$-phases of LiFe5O8. Phys. Rev. B 2011, 84, 094111. [CrossRef]

27. Ivanov, V.G.; Hadjichristov, G.; Faulques, E. Characterization of chemical bonding in ion-implanted polymers by means of mid-infrared reflectivity. Appl. Spectrosc. 2009, 63, 1022-1026. [CrossRef] [PubMed]

28. Joseph, J.; Jemmis, E. Red-, blue-, or no-shift in hydrogen bonds: A unified explanation. J. Am. Chem. Soc. 2007, 129, 4620-4632. [CrossRef]

29. Qian, W.; Krimm, S. Limitations of the molecular multipole expansion treatment of electrostatic interactions for $\mathrm{C}-\mathrm{H} \odot \odot \odot \mathrm{O}$ and $\mathrm{O}-\mathrm{H} \odot \odot \odot \mathrm{O}$ hydrogen bonds and application of a general charge density approach. J. Phys. Chem. A 2005, 109, 5608-5618. [CrossRef]

30. Gu, Y.; Kar, T.; Scheiner, S. Fundamental properties of the $\mathrm{CH} \odot \odot \odot$ O interaction: Is it a true hydrogen bond? J. Am. Chem. Soc. 1999, 121, 9411-9422. [CrossRef]

31. Masunov, A.; Dannenberg, J.J.; Contreras, R.H. C-H bond-shortening upon hydrogen bond formation: Influence of an electric field. J. Phys. Chem. A 2001, 105, 4737-4740. [CrossRef]

32. Wang, T.-H.; Hsu, L.-W.; Chang, H.-C. Structural reorganization of imidazolium ionic liquids induced by pressure-enhanced ionic liquid-Polyethylene oxide interactions. Int. J. Mol. Sci. 2021, 22, 981. [CrossRef]

33. Wang, T.H.; Shen, M.H.; Chang, H.C. Pressure-dependent stability of imidazolium-based ionic liquid/DNA materials investigated by high-pressure infrared spectroscopy. Materials 2019, 12, 4202. [CrossRef]

34. Chang, Y.-H.; Chang, H.-C.; Fu, Y.-P. Utilizing infrared spectroscopy to analyze the interfacial structures of ionic liquids/Al2O3 and ionic liquids/mica mixtures under high pressures. Nanomaterials 2019, 9, 373. [CrossRef]

35. Wang, T.-H.; Lin, E.-Y.; Chang, H.-C. Pressure-dependent confinement effect of ionic liquids in porous silica. Nanomaterials 2019, 9, 620. [CrossRef] [PubMed]

36. Wang, T.-H.; Wu, M.-S.; Chang, H.-C. Characterization of local structures of confined imidazolium ionic liquids in PVdF-co-HFP matrices by high pressure infrared spectroscopy. Nanomaterials 2020, 10, 1973. [CrossRef] [PubMed]

37. Wong, P.T.T.; Moffatt, D.J. The uncoupled O-H or O-D stretch in water as an internal pressure gauge for high-pressure infrared spectroscopy of aqueous systems. Appl. Spectrosc. 1987, 41, 1070-1072. [CrossRef]

38. Wong, P.T.T.; Moffatt, D.J.; Baudais, F.L. Crystalline quartz as an internal pressure calibrant for high-pressure infrared spectroscopy. Appl. Spectrosc. 1985, 39, 733-735. [CrossRef]

39. Tsuzuki, S.; Tokuda, H.; Hayamizu, K.; Watanabe, M. Magnitude and directionality of interaction in ion pairs of ionic liquids: Relationship with ionic conductivity. J. Phys. Chem. B 2005, 109, 16474-16481. [CrossRef] 